\title{
MUDAR, PENSAR EM MUDAR, CONTINUAR MUDANDO: NARRATIVAS DAS METAMORFOSES DE UMA ADOLESCÊNCIA EM ABRIGAMENTO
}

\author{
CAMBIAR, PENSAR EN CAMBIAR, SEGUIR CAMBIANDO: \\ NARRATIVAS DE LAS METAMORFOSIS DE UNA ADOLESCENCIA \\ EN CUIDADO INSTITUCIONAL \\ TO CHANGE, TO THINK ABOUT CHANGING, TO KEEP CHANGING: \\ NARRATIVES OF THE METAMORPHOSES OF A \\ SHELTERED ADOLESCENCE
}

\section{Júlia Loren dos Santos Rodrigues ${ }^{1}$, Larissa Medeiros Marinho dos Santos $^{1} \mathrm{e}$ Aluísio Ferreira de Lima ${ }^{2}$}

\author{
${ }^{1}$ Universidade Federal de São João del Rei, São João del Rei/MG, Brasil \\ ${ }^{2}$ Universidade Federal do Ceará, Fortaleza/CE, Brasil
}

\begin{abstract}
RESUMO: As investigações acerca das políticas direcionadas para crianças e adolescentes constituem-se como um campo de análise que requer avaliações constantes sobre seus efeitos práticos e ideologias estruturantes. Considerando o cuidado com a identidade dos sujeitos acolhidos, disposto no Estatuto da Criança e do Adolescente, desenvolveu-se uma análise sobre o processo de metamorfose identitária de um adolescente que, há mais de oito anos, reside em uma Unidade de Acolhimento Institucional. Para relatar a pesquisa, iniciou-se com uma breve revisão sobre o histórico dos modelos de acolhimento no Brasil, uma análise sócio-histórica da adolescência e a descrição da concepção identidademetamorfose-emancipação. O participante da pesquisa, José Miguel, narrou a sua história de vida trazendo elementos fundamentais para a reflexão acerca dos papéis dos atores institucionais, a demanda por afeto e sobre as resistências sociais e institucionais na vivência de uma sexualidade em "processo de transição".

PALAVRAS-CHAVE: Identidade; Narrativa; Acolhimento institucional; Adolescência; Gênero.
\end{abstract}

RESUMEN: Las investigaciones acerca de las políticas para niñas/os y adolescentes se constituye como un campo del análisis que requiere evaluaciones constantes sobre sus efectos prácticos e ideologías estructurantes. Considerando el cuidado con la identidad de los sujetos acogidos, dispuesto en el Estatuto del Niño y del Adolescente, se desarrolló un análisis sobre el proceso de metamorfosis identitaria de un adolescente que hace ocho años reside en una Unidad de Acogimiento Institucional. Para relatar la investigación, se inició una breve revisión sobre el histórico de los modelos de acogida en Brasil, un análisis sociohistórico de la adolescencia y la descripción de la concepción identidadmetamorfosis-emancipación. El participante de la investigación, José Miguel, narró su historia vida trayendo elementos fundamentales para la reflexión acerca de los papeles de los actores institucionales, la demanda por afecto y sobre las resistencias sociales e institucionales en la vivencia de una "sexualidad en transición".

PALABRAS CLAVE: Identidad; Narrativa; Acogida institucional; Adolescencia; Género.

ABSTRACT: Research on policies directed to children and adolescents is a field of analysis that requires constant assessments of its practical effects and structuring ideologies. Considering the care with the identity of the hosted subjects, as established in the Statute of the Child and the Adolescent (ECA), an analysis was developed on the process of identity metamorphosis of an adolescent who, for more than eight years, has resided in a Unidade de Acolhimento Institucional (Unit of Institutional Hosting). To report the research, we began with a brief review of the history of host models in Brazil, a socio-historical analysis of adolescence and the description of the identitymetamorphosis-emancipation conception. The research participant, José Miguel, narrated his life history bringing fundamental elements for the reflection on the roles of institutional actors, on the demand for affection and on social and institutional resistance in the experience of a sexuality in a "transitional process".

KEYWORDS: Identity; Narrative; Institutional hosting; Adolescence; Gender. 


\section{Introdução}

No ano de 2013, o Ministério Público divulgou um relatório técnico com dados nacionais sobre as unidades acolhimento, possibilitando a criação de um perfil nacional acerca do funcionamento das instituições. Nesse relatório, foi elucidado que havia no Brasil de 2012 e 2013, respectivamente, 1.691 e 2247 Unidades de Acolhimento Institucional, sendo 1277/1736 Abrigos institucionais, 414/511 Casas-Lares, sendo que a maioria dos abrigos estavam localizados na região Sudeste, e as Casas-Lares na região Sul. Outros dados importantes também foram divulgados no relatório, demonstrando que a maioria das crianças e dos adolescentes são acolhidos devido à negligência e/ou por terem pais ou responsáveis dependentes químicos e alcoolistas. No que tange a faixa etária nacional constatou-se "maior incidência de meninos entre 6 e 11 anos e meninas de 6 a 11 anos e 12 a 15” (Conselho Nacional do Ministério Público, 2013, p. 36).

Destaca-se que os três estados com maior concentração de entidades são, respectivamente, São Paulo, Minas Gerais e Paraná. Além disso, os dados entre os anos de 2013 e 2018 demonstram que a quantidade de Unidades de Acolhimento teve um acréscimo de 197,46\%, e que as localidades que mais cresceram foram aquelas localizadas em contextos de significativa industrialização. De acordo com Venâncio (2000), acerca da ausência de práticas de destituição familiar nas comunidades campesinas, observa-se a existência de uma relação entre o crescimento das práticas industriais e tecnológicas e o crescimento das metrópoles com o aumento significativo das entidades e acolhimento.

O Estatuto da Criança e do Adolescente (ECA) (Lei n. 8069 de 1990) é o documento que prioritariamente ordena e orienta as práticas e os modos de organização das Unidades de Acolhimento Institucional. Segundo o ECA, as crianças e os adolescentes poderão ser a afastadas da família de origem somente após a realização de inúmeras tentativas de manutenção do vínculo familiar e; ao entrarem em uma Unidade de Acolhimento as crianças deverão ter acesso a um serviço orientado pela lógica da proteção integral, acesso e bens materiais e de consumo, educação, saúde e cuidado afetivo.

Durante o processo de Acolhimento Institucional e orientando-se para a oferta de um cuidado integral aos sujeitos em acolhimento, o ECA (Lei n. 8069/90) prevê em seu artigo $94, \S 4^{\circ}$ como obrigação dessas instituições a preservação da identidade dos indivíduos acolhidos. A legislação nos remete ao olhar da psicologia social crítica e, inspirados pelo olhar de Ciampa (1987/2005), considera-se que dizer sobre a preservação da identidade soa contraditório, visto que essa se expressa enquanto metamorfose, e não como algo estático ou elemento definidor, universal e estável dos sujeitos humanos. Contudo, apesar da utilização do termo "preservação", foi possível acessar essa medida enquanto uma estratégia de cuidado, uma vez que na descrição prática dessa atividade há espaço para o movimento de metamorfose da identidade. Segundo o documento de Orientações Técnicas, destinadas aos serviços de acolhimento institucional, institui-se como o cuidado com identidade dos sujeitos acolhidos o respeito e o resgate de elementos das suas histórias de vida. O texto prescreve que:

o atendimento deverá ser oferecido para um pequeno grupo e garantir espaços privados, objetos pessoais e registros, inclusive fotográficos, sobre a história de vida e desenvolvimento de cada criança e adolescente. A organização de condições 
que favoreçam a formação da identidade da criança e do adolescente implica o respeito à sua individualidade e história de vida. (Conselho Nacional dos Direitos da Criança e do Adolescente, 2009, p. 21)

O cuidado com a narrativa de história de vida e a ênfase dada à importância de uma manutenção das subjetividades, objetivadas nas fotografias e na privacidade do espaço, demonstram que a investigação acerca da identidade-metamorfose de sujeitos que estão em acolhimento institucional pode fornecer frutos e vislumbres proveitosos para o desenvolvimento das políticas públicas de acolhimento que estejam em consonância com os desafios que perpassam o afastamento familiar e institucionalização.

O resgate dos registros bibliog ráficos de pesquisas realizadas em unidade de acolhimento demonstra uma contradição referente aos sentidos atribuídos à institucionalização, pois ora estão associados ao desamparo, ao sofrimento, aos estigmas, e ora são relacionados ao acesso a alimentação, ao conforto e à moradia (Luvizaro \& Galheigo, 2011; Oliveira, 2007; Santos \& Boucinha, 2011). Muitas dessas crianças e adolescentes chegam à instituição apenas com a roupa do corpo e/ou poucas lembranças objetivadas. Sentem-se aliviados por encontrarem uma cama e alimentos disponíveis, mas ao mesmo tempo sentem-se sequestrados da família, distanciados do afeto. Será sempre um desafio compreender a forma como o alívio, a dor, a saudade e a esperança se manifestam em sujeitos acolhidos e afetam o seu modo de serem reconhecidos no mundo e reconhecerem a si mesmo. Contudo, atentar-se para a história de vida e percebê-los como um "sendo" constitui-se como convite a um reconhecimento libertário e ao empreendimento de emancipação.

Conforme assinala Lima (2012), o exercício de pesquisar a identidade na perspectiva da psicologia social "deve ser um convite para a inquietação, para o inconformismo, para a subversão do instituído e, sobretudo, para o vislumbre e a criação de alternativas para as alternativas que não têm transformado a nossa sociedade" (p. 226). Portanto, concernentes às contradições que aparecem nas pesquisas acerca dos sentidos sobre o acolhimento, recorreu-se às proposições de Ciampa (1987/2005) para nortear o estudo da identidademetamorfose de um adolescente que está em contexto de acolhimento institucional por pouco mais de oito anos.

As acepções defendidas por Ciampa (1987/2005) que tratam a questão da identidade como atividade e história, em detrimento de concepções naturalistas e fixadoras, levaram a uma nova compreensão nos processos de investigação sobre o que é ser sujeito, especificamente, a proposição de que, a despeito de qualquer concepção essencialista ou cristalizada, a identidade é inevitavelmente metamorfose. O sujeito, produtor e produto da própria história e da sociedade, insere-se em um movimento dialético, no qual objetiva e subjetivamente firma-se enquanto processo confluente e inexorável. O estudo da identidade-metamorfose atenta-se para a história, cultura, economia, política, ideologias, bem como para os sentidos, os sentimentos e as experiências individuais. A identidade humana passa a ser compreendida como uma identidade social que, associada à aquisição de uma consciência histórica, torna-se possível alcançar a consciência de si e vivenciar percursos emancipatórios (Lane, 1984/2012).

Considerando que identidade é história e atividade, Ciampa (1987/2005) estabeleceuse como estratégia metodológica de investigação identitária em movimento a escuta e análise das narrativas das histórias de vida. Postulou que, por meio das histórias de vida, 
seria possível perceber os movimentos de mesmice e mesmidadade, e assim perceber os recursos emancipatórios, as políticas de identidade (Ciampa, 2002), as (con)tradições sociais, as metamorfoses e o contex to histórico social no qual o indivíduo está inserido.

Estudar a identidade é, na perspectiva de Ciampa (1987/2005), investigar como cada personagem, representado nas relações interpessoais, é conceituado no espaço e no tempo em um ambiente que é permeado por relações históricas, sociais, culturais e econômicas, com o objetivo de identificar quais os esquemas classificatórios que tentam, a todo instante, normatizar e estabilizar a possibilidade de emancipação do ser. Identidade é expressão de um aspecto real, material, sujeita a transformação e a ela deve ser atribuída ao exercício de uma ação, que diz do passado, presente e futuro do sujeito, e que não limita as possibilidades de ressignificar o que já foi, está sendo e pretende ser.

Importante destacar também que, aliado ao olhar para identidade-metamorfoseemancipação, a adolescência é aqui considerada, a partir da perspectiva sócio-histórica, como um fenômeno vinculado às metamorfoses identitárias do participante da pesquisa. Assume-se, por isso, a impossibilidade de compreender a adolescência como um fenômeno universal e natural e afirmando-a como uma construção perpassada pela cultura, economia, política, biologia, sociedade e ideologia (Aguiar, Bock \& Ozella, 2007).

Os adolescentes foram e ainda são, em diferentes momentos, consagrados como sujeitos sociais em situação de risco e requisitantes por tutela (Ferreira, Aznar-Farias, \& Silvares, 2010). A confluência entre a definição de puberdade e adolescência traduziram as transformações biológicas e hormonais ocorridas na puberdade como sinais de alerta para a ocorrência de comportamentos vexatórios e inadequados. Essa preocupação desvela tanto as dificuldades sociais ao lidar com temáticas tabus como a sexualidade (Reis \& Zioni, 1993), ao passo que também demonstra os interesses de regulação social voltados para o capital (Gonçalves, Lima, Miranda, \& Costa-França, 2014).

Contudo, a concepção da adolescência como um dado ahistórico demonstra a precocidade e a irreflexão da apreciação sobre esses sujeitos (Mayorga, 2006). Ao passar a considerar como etapas da vida, a infância, a adolescência, a fase adulta e a velhice não foram criadas apenas nomenclaturas e divisões, mas também sentidos. Todo registro simbólico é uma construção social e histórica, de modo que ser adolescente não é uma simples demarcação biológica e cronológica, mas um papel/registro social.

Concernente à percepção das contradições internas, a concepção da adolescência como um dado natural orientou-se ao longo da pesquisa por uma crítica da concepção naturalista e biologicista da adolescência pelo viés da psicologia sócio-histórica. Admitiuse a adolescência como "uma construção social com repercussões na subjetividade e no desenvolvimento do homem moderno e não como um período natural do desenvolvimento. É um momento significado, interpretado e construído pelos homens" (Bock, 2007, p. 68).

O delicado e necessário encontro entre identidade e adolescência se recompôs pela via da negação do entendimento dessa fase enquanto uma etapa de crise e uma aproximação a "concepção de identidade como um processo de metamorfose que ocorre constantemente ao longo da vida", representando assim um "momento em que se inclui a possibilidade de criar princípios e que libertem o desempenho de papéis de uma heteronomia coercitiva, através de uma autonomia criativa” (Alves, 1997a, p. 24). 
Este relato de pesquisa foi construído pelo questionamento acerca do processo de metamorfose identitária de um adolescente, atentando-se para a análise crítica da história de vida por ele relatada e às interfaces decorrentes das relações institucionais imbricadas nesse processo, considerando que as condições que produzem e orientam a institucionalização assumem um papel preponderante no movimento de fazer-se do indivíduo.

\section{Metodologia}

A pesquisa foi guiada pelo método qualitativo, caracterizando a realização do estudo como um encontro entre o pesquisador, pesquisado e o contex to social em que ambos estão situados, o que possibilita a construção de resultados úteis à ciência e à sociedade. Minayo e Deslandes (2007) indicam a metodologia qualitativa para aqueles que almejam trabalhar com "o universo dos significados, dos motivos, das aspirações, das crenças, dos valores e das atitudes" (p. 21), o que corresponde à proposta investigativa desta pesquisa.

Objetivando compreender as metamorfoses identitárias de um adolescente que vive em uma unidade de acolhimento institucional, utilizou-se como estratégia investigativa a escuta e a análise da "narrativa da história de vida", organizada por Lima (2014) e proposta inicialmente por Ciampa (1987/2005). A compreensão acerca do fato de que "ao contar sua vida, o sujeito fala de seu contexto - fala do processo por ele experimentado, intimamente ligado à conjuntura social onde ele se encontra inserido" (Silva, Barros, Nogueira, \& Barros, 2007, p. 32), acrescida à afirmação de Ciampa (1987/2005), para quem "uma identidade nos aparece como a articulação de várias personagens, articulação de igualdades e diferenças, constituindo, e constituída por uma história pessoal” (p. 163), deram sustentação a seleção da narrativa como ferramenta apropriada para a investigação.

Foram realizadas duas entrevistas com o participante da pesquisa, totalizando aproximadamente duas horas de gravação em áudio, que foram integralmente transcritas. A análise da narrativa foi orientada por teóricos aliados à psicologia social crítica, tendo como destaque as publicações de Ciampa (1987/2005), Alves (1997b), Lima (2010), Goffman (2014), Honneth (2009), Butler (2015a, 2015b), entre outros.

A instituição na qual o participante da pesquisa reside está localizada em uma cidade interiorana e segue a modalidade de Abrigo Institucional. Havia, no momento de realização da pesquisa, dez crianças e adolescentes acolhidos, e a equipe era formada por uma coordenadora, oito cuidadoras que alternam em dias e horários de trabalho, uma psicóloga e uma assistente social. A unidade conta com o apoio da Prefeitura Municipal e de uma instituição não governamental vinculada.

O participante da pesquisa foi selecionado após a realização de entrevistas com todos os cinco adolescentes residentes na instituição, sendo que, por objetivar um estudo aprofundado, optou-se apenas pela história de José Miguel, que, naquele momento, estava com quinze anos. A devolutiva foi individual e todos os adolescentes participantes receberam um livro com a transcrição da própria narrativa, sendo essa considerada uma contribuição direta da pesquisa aos sujeitos de acolhidos.

A pesquisa foi avaliada e aprovada pelo Comitê de Ética em Pesquisa Envolvendo Seres Humanos - Unidades Educacionais da Universidade Federal de São João del Rei, MG, com parecer de $\mathrm{n}^{\circ}$ 2.413.773, e todos os entrevistados e o responsável legal pelos adolescentes receberam e assinaram, respectivamente, o Termo de Assentimento e Consentimento Livre e Esclarecido. 


\section{Resultados e discussão}

As dimensões históricas, políticas e simbólicas da institucionalização, a vivência sócio-histórica da adolescência e a identidade-metamorfose foram temáticas de referência para construção do olhar analítico-compreensivo da história de José Miguel ${ }^{1}$.

A história de vida de José Miguel solicitou uma estratégia de análise e organização da narrativa um pouco diferente daquela utilizada nas pesquisas de identidade-metamorfose, que são demarcadas personagens (Almeida, 2005; Ciampa, 1987/2005; Lima, 2010). Optouse pela seleção de ensaios identitários, considerando as fragmentações das narrativas, bem como o modo escolhido por José Miguel de enunciá-las a partir da seleção de momentos e temáticas que lhe marcaram.

Inspirados em Goffman (2014), neste estudo, os ensaios foram classificados como possibilidade de testar personagens, avaliar-se nessa posição de atuação e reconfigurar-se. Expressam-se neles toda a dimensão da peça teatral, e destaca-se o caráter de análise de todas as formatações planejadas, uma vez que as executa em sua concretude. Neste ponto, depreende-se que ensaiar é agir e que a atividade desempenhada é identidade.

Como a narrativa de toda história de vida não poderia ser abarcada em um único artigo, foram selecionadas as temáticas de maior relevância social que compuseram a narrativa e que possibilitaram a reflexão e a elaboração de novas estratégias de cuidado às crianças, aos adolescentes e aos familiares. Por destacar com tanta veemência, ao longo da narrativa, os transcursos enfrentados entre ser algo, pensar em se transformar e pensar se deverá continuar se transformando, observou-se que José Miguel está vivenciado com coragem a possibilidade de ser metamorfose disposta a emancipação.

Dessa forma, para iniciar a apresentação dos ensaios identitários de José Miguel, descreve-se, em um primeiro momento, um contexto aos trechos que serão destacados para narrar, ainda que brevemente sua a história. Importante ressaltar que as informações que darão contextualização aos fragmentos da história são oriundas da própria fala de José Miguel ao longo das entrevistas realizadas.

A história de vida de José Miguel é iniciada com a descrição de um percurso de migrações. Sua mãe, atuante no contexto do tráfico, necessitava em diferentes momentos mudar de cidade e casa. O início da história é demarcado por migrações, as quais eram justificadas por aquilo que José Miguel chamou de "suposto trabalho" da mãe, e que posteriormente estaria vinculada ao rompimento do vínculo com a família de origem.

Sobre este fato, assinala-se ainda a relevância social incluída no debate entre o uso prejudicial de álcool e outras drogas e as possíveis correlações com o tráfico e o cenário atual dos processos de acolhimento institucional no Brasil. Esta é uma das principais questões indicadas como um motivo que leva ao acolhimento (Conselho Nacional do Ministério Público, 2013) e desperta uma reflexão acerca da responsabilização individual como alternativa ao reconhecimento da moral do Estado, do mercado e o da criminalização das drogas. Questiona-se como pensar criticamente a realidade familiar, social, cultural, econômica e histórica que se organiza contraditoriamente, gerando vias de trabalho criminalizáveis e ações de repressão a essa atividade centradas em uma moral individual, de modo que a institucionalização de crianças e adolescentes não seja vista como uma resposta satisfatória frente a mazelas socialmente sustentadas? 
Após a introdução dos seus registros migratórios, José Miguel relata, que aos oitos anos, enfrentou a sua entrada em um contexto de acolhimento institucional. Nesse momento, ele foi abrigado juntamente com sua irmã Ana, de aproximadamente cinco anos, em uma Casa-Lar que, com o passar dos anos, foi recebendo um maior número de crianças até o ponto em que se formalizou como Abrigo Institucional. Ainda nessa Casa-Lar, José Miguel conheceu e desenvolveu uma amizade com Olívia, uma adolescente que naquele momento tinha cerca de quinze anos e que tinha o hábito de ir voluntariamente à Casa para brincar com as crianças.

Importante mencionar também que José Miguel traz em sua história os estigmas encarnados por aqueles que algum dia foram diagnosticados com algum transtorno/doença de ordem psicológica. A té o momento em que a entrevista foi realizada, José Miguel tomava diariamente medicações psiquiátricas e já havia passado por um período de internação em um hospital psiquiátrico. Grande parte da narrativa de resistência de José Miguel é perpassada por uma defesa da coerência dos seus pensamentos e desejos. Em vários momentos, ele questionava se a postura que ele estava assumindo junto a entrevistadora era adequada, se as palavras estavam "bonitas", chegando até a pedir desculpas em uma das entrevistas dizendo: "desculpa tá falando eeeee... é porque o efeito do Haldol faz isso". O caminho da entrevista, da escuta e da espera frente aos silêncios de José Miguel trouxe então um novo tom: as pausas constantes, pois já não eram mais uma falha, mas uma mensagem da sua história.

Por esta introdução, poderiam ser destacados vários nomes que reduziriam e ocultariam quem é José Miguel, mas esse não foi o caminho escolhido. Aquilo que José Miguel contou em movimento ao longo das entrevistas é um convite a uma leitura que solicita a suspensão de impressões pré-formatadas, pois para conhecer José Miguel em toda sua ação de reflexão e transformação é necessário sair do lugar comum. Portanto, parte-se, agora, para um movimento de descoberta por vicissitudes.

Antes de dar início a escuta da história, recorreu-se, apesar do risco de substantivação, a pergunta: Quem é você? para que sequencialmente pudesse ser descrita a história de vida que levou a essa concepção de si e, assim, quebrar o substantivo e iniciar a ação verbalizadora da identidade-metamorfose. A essa primeira pergunta, José Miguel respondeu dizendo o próprio nome e esclarecendo que esse significava ser alguém que está a "se superar cada vez mais", mas também acrescentou:

Quem sou eu? (pausa). Uma pessoa que perdeu a esperança... que num... que perdeu os amigos... não tenho mais ninguém pra contar. Não tenho mais ninguém pra poder compartilhar essas coisa. É isso... uma pessoa que perdeu seus amigos... que perdeu o respeito, perdeu o respeito das pessoas.

O destaque da "superação" como característica fundamental na descrição de si mesmo revela a postura crítica de José Miguel ao perceber tanto os limites quanto a potência de ser quem ele é. $\mathrm{O}$ acréscimo a sua descrição, feito em um segundo momento de escuta da narrativa, demonstrou as dificuldades de reconhecimento que ele tem enfrentado. Ser aquele que perdeu a esperança, os amigos e respeito se estrutura a partir de quebras nas relações sociais com pessoas amadas relatadas por José Miguel. 
É assim que eu me vejo, depois que a... eu não tô dizendo que a culpada disso tudo é a Olivia... a culpa disso tudo fui eu... tenho consciência disso... culpada, o culpado disso tudo fui eu ...e eu vejo que a Olívia tá certa... de ter, de ter se afastado de mim, porque ela... Ela deve ter pensado assim: eu vou me afastar que isso não tá fazendo bem pra ela.

A quebra do vínculo que José Miguel teve com Olívia é uma temática que se repete em vários instantes da narrativa, mas havia ainda outras perdas, como o vínculo com a mãe. De um modo geral, havia a perda de uma permanência, desafio enfrentado nos contextos de institucionalização que suscitam questionamentos acerca dos efeitos das relações superficiais, sobre os impactos da falta de uma presença, de alguém que possa estar para além de uma obrigação, de um ideal religioso ou de uma permissão institucional.

No que tange à quebra do vínculo familiar, sabe-se que este é um fator preditivo para a oferta de acolhimento institucional, o que denuncia a necessidade de que a política pública voltada para assistência e acolhimento de crianças e adolescentes reflita constantemente sobre a importância de atentar-se às subjetividades. Não basta oferecer comida, moradia, saúde e educação. Ser humano demanda por afeto, por vínculo, por amor. Inclusive, José Miguel pontua sobre a sua experiência atual:

Ah, eu tenho vivido um dia de cada vez, né? Porque... pra mim não é fácil ser uma
pessoa que eu tô sendo hoje. Uma pessoa desobediente, sem educação, sem limite. E tudo
isso é culpa minha. Não é que eu tô escolhendo, as circunstâncias tão fazendo com que
eu escolha. Porque eu sinto falta de conversar com alguém assim, igual eu converso com
você. Eu sinto falta de sair, pra... pra poder ter aquelas brincadeiras, igual eu tinha com
o Gustavo (esposo da Olívia), com a... com a... Olívia. Que a gente brincava de balão
de guerra d'água.

Hoje, José Miguel tem muito daquilo que lhe faltou na infância, como alimento, moradia e condições de ir à escola, mas certamente para a condição de ser humano isso não é tudo o que se necessita. É imprescindível ter alguém para conversar, ter alguém para brincar de "balão de guerra d'água”.

Pensando sobre o que aparece para José Miguel como justificava para aquilo que explica parte dos vínculos rompidos, ressoa a afirmação de Butler (2015a) sobre o fato de que "a condição de ser reconhecido precede o reconhecimento" (p. 19), sendo que essas condições são historicamente "articuladas e reforçadas" (p. 18). Por essa razão, fazse necessário refletir sobre as condições de reconhecimento que levam José Miguel a se perceber inicialmente como aquele que "se supera cada vez mais" e o deslocamento desse lugar para aquele de quem "perdeu a esperança, os amigos e o respeito". As alusões sobre essa mudança frente ao que foi narrado se traduzem na própria narrativa quando, nesse segundo momento, José Miguel se percebeu afastado daqueles que amava, "havia causado decepções" e agora estava sozinho. Interpreta toda a situação como sendo de sua própria responsabilidade, ainda que houvesse vários atores compartilhando a cena com ele.

Continuando o relato acerca de Olívia, ele traz na narrativa a lembrança do primeiro encontro, rememorando detalhes daquele momento: "Ela tava de calça jeans, um fone branco, uma blusa de frio branca, um capuz, uma mochila preta. Ela foi lá brincar... ela foi lá conhecer eu e minha irmã. E... o nosso santo bateu”. Contudo, a relação de Olívia e José Miguel foi barrada pelo surgimento de um amor sexual unilateral, pois apenas José Miguel havia se apaixonado, o que ultrapassou o vínculo fraterno e comunitário. Ao contar sobre esse 
fato, José Miguel afirma ser ele a "culpa”. Antes mesmo de ser o culpado - alguém que descumpre a ordem - ele é a "culpa" - a fonte do descumprimento, o problema inerente. Nesse instante, refaz-se, então, as reflexões de Butler (2015a) sobre a essencialidade da precariedade humana. Dependemos sempre de um outro, mas no fluxo dessa relação não há necessariamente reciprocidade e codependência, podendo se tornar a "culpa" aquele que sofre por não se adequar a norma. Sendo assim, os ensaios de José Miguel de ser aquele que "se supera cada vez mais" e ser aquele "que perdeu a esperança, os amigos e o respeito" se lançam no espaço sócio-histórico na aposta de transformar e enfrentar a norma com vista a sobrevivência da alteridade emancipatória.

As marcas da inadequação do seu modo de ser aparecem para ele pela via do olhar do outro, desde a sua infância, quando relata que:

Na rua, as pessoas, me olhavam... naquela época elas me olhavam com um olhar de discriminação, né? Porque eu ainda tava em processo de transição e ainda tô (quando era criança...) as pessoas perguntavam assim, que sempre andava, sempre fui o machinho. Sempre andei na rua só de bermuda, de descalço, sem blusa, cabelo solto. As pessoas perguntavam se eu era... e eu sempre tava no meio dos menino ... E as pessoa perguntava se eu era menino, menina e eu não falava nada.

José Miguel vivenciou, desde períodos anteriores a institucionalização, episódios de discriminação vinculado a sua identidade sexual. Atualmente, vivendo a adolescência encarando as mudanças na estrutura e funcionamento corporal e sendo perpassado por demandas sociais de responsabilização - ele descreve com maestria, após ser questionado sobre o significado do termo, o que nomeia com processo de transição ao dizer:

É... processo de mudar, de mudar, de pensar em se mudar ou de pensar em continuar sendo a mesma pessoa. É meio confuso, né? Porque ó... Se eu for José Miguel... as pessoas vão me criticar. Talvez eu não vou ter emprego. Porque as pessoas olham muito o jeito das outras pessoas se vestir. É... se eu for Maria, eu vou tá sendo infeliz.... porque, porque... (pausa) ah, eu não sei te explicar, não.

A sexualidade de José Miguel aparece como questão desde a infância. Ser alguém diferente do padrão socialmente esperado, uma fuga às normas hegemônicas culturais, gerou dúvidas sobre o que se deve ser (Buttler, 2015b). Contudo, corajosamente, ele continua mudando, pensando em mudar e pensando em continuar mudando. Traduz, assim, uma identidade que é pura metamorfose e também resistência e emancipação.

Entretanto, frente ao seu relato de resistência, José Miguel apontou um entrave dizendo que "As pessoas acham que eu não tenho opinião própria. Só que eu tenho”. Muitas vezes, José Miguel é questionado sobre a sua decisão, inclusive ele relatou que deseja fazer uma terapia de hormonização, mas que só poderá fazê-la ao sair da instituição, pois terá completado 18 anos - marco cronológico de finalização da adolescência segundo o ECA. A percepção de que os outros acreditam que ele não tem opinião própria e que decisões importantes só poderão ser tomadas com a maioridade remontam a crítica sobre a concepção naturalizante e biologicista que se tem sobre a adolescência. Como afirma Aguiar, Bock e Ozella (2007, p. 107) “os adolescentes já possuem todas as possibilidades de se inserir na sociedade adulta, em termos cognitivos, afetivos, de capacidade de trabalho e de reprodução. No entanto, a sociedade adulta pouco a pouco lhe tira a autorização para sua inserção". 
Além disso, as marcas deferidas do seu diagnóstico psiquiátrico também podem ser analisadas, em alguma medida, enquanto um fenômeno que produz ruídos para compreensão do seu desejo e concepções. Ruídos que são sustentados pelo preconceito e pela ausência de um raciocínio crítico que viabilize o alcance da consciência de si. O lugar do discurso do "louco" é tomado como um registro de fala que deve ser posto à prova pela ausência de um raciocínio admitido como normal. Contudo, conforme afirma Lima (2010, p. 173), a validade de um discurso pode ser mais bem explicada pelo reconhecimento intersubjetivo em condições que lhe foram favoráveis, sendo que a tomada de um discurso como sendo válido enuncia mais um posicionamento do que um alcance de uma razão ou factibilidade indubitável. Assim, indaga-se em que medida é possível sustentar dogmas de uma razão lógica para colocar um discurso à prova? Visto que, pelo viés de um racionalismo que pretende definir discursos enquanto normais/aceitáveis e patológicos/inaudíveis, recai-se em um ato de discriminação, no qual a validade dos atos de fala e dos modos de ser são determinadas por padrões excludentes e acríticos.

Todavia, apesar das barreiras percebidas, José Miguel resiste no ensaio de uma personagem que por vezes é admitida como violenta pelos agentes da instituição e crianças e adolescentes que convivem com ele, mas que é forte o suficiente para manter suas convicções e, por isso, declara sobre quando lhe perguntam se ele é menino ou menina:

\begin{abstract}
Eu falo que eu sou menino. Que eu nasci no corpo de uma menina, mas que eu me considero como menino. (Sou) O José Miguel que é transexual. Qué dizê. Ainda, por enquanto, não sou transexual, não. Porque eu não me transformei ainda não. Sou homossexual.
\end{abstract}

E... o que me admira num homem, o que eu quero pra mim, que eu quero ser um homem, um homem do jeito que eu te falo agora. Um homem que não bate em mulher. Aquele homem que... que... escuta mais as mulheres, que escuta mais os próximos. É... que num... que... que não pensa só em si, pensa no próximo também.

Entende-se que o processo de transição descrito por José Miguel, não está referenciado apenas na vivência da sua sexualidade. Parte dela, mas a transcende. Ser homem, não é apenas poder desejar uma mulher e usufruir desse desejo. É também poder ser alguém que hoje ele não tem conseguido ser e que identifica como uma justificativa para o afastamento daqueles que ele tanto ama. Ser homem é pensar no próximo, é ser educado. É saber escutar mais as mulheres, respeitar e poder ser admirado. Ser homem é emancipar-se de pressuposições violentas e perversas destinadas a ele.

Além do "processo de transição", outro aspecto central no relato da história de vida de José Miguel constitui-se na descrição dos atores institucionais "como se fossem mães" e que remonta a discussão tecida acerca da permanência dos vínculos. A repetição dessa caracterização ao longo da narrativa possibilitou reflexões sobre a busca orientada pelas diversas políticas de acolhimento (Lei n. 8069/90; Conselho Nacional dos Direitos da Criança e do Adolescente, 2009) de que as Unidades devem assemelhar-se ao convívio familiar. Sobre a possibilidade de criar um contexto familiar e consequentes vínculos, José Miguel narra:

A Paula, a Amélia e a Amanda (são como mães) porque... porque nos momentos mais difíceis era elas que esteve comigo. Eu não vou falar que a Olívia eu considero como mãe, porque ela não tem nem idade, né? Ela também foi uma parte muito importante da minha vida. 
Brenda (irmã mais velha) foi como uma mãe. Porque ela cuidou de mim. Levava pra escola, dava banho... deixava eu faltar de aula. (risos)

Para explicar o que é ter alguém como mãe, José Miguel diz que:

Pra mim é uma sensação boa. Uma sensação boa e ruim. É uma sensação muito boa, né? Porque cê se sente amado. Boa. Porque... porque... porque... ela... apesar... por que eu tenho mania de falar que elas trabalham aqui só por causa do dinheiro. Quando eu tô com raiva. Mas não é. Elas mostram carinho por nós. E a ruim... é porque elas chamam atenção, negócio assim. E a ruim é porque a tia Amélia foi embora e nos abandonou, né?

E ainda pontua que ser "como se fosse" mãe refaz-se integralmente como ser uma mãe em certos casos e em outros, não.

Alguns casos... tipo, no caso da minha irmã Brenda, é sim! No caso das outras pessoas, não. Porque não são do meu sangue. Eu não sinto totalmente à vontade. (quando é do mesmo sangue) cê tem uma metade da sua mãe perto de você.

O não se sentir "totalmente à vontade" e a descrição de "como se fosse" trouxeram para a análise da narrativa a performatividade dos atos de fala descrito por Austin (1990) e condizentes com a concepção de identidade como metamorfose. Quando a política diz que as instituições devem promover um espaço semelhante ao convívio familiar, enuncia performaticamente a requisição de uma política de identidade que possa replicar em papéis formas de idealizações sociais. Contudo, a política e as instituições malogram em suas tentativas, por não poderem sustentar o lugar de família idealizada e utópica e também pela fragilidade do vínculo, já que muitos vão embora, como ocorreu com a Amélia (funcionária da instituição) e Olívia. "Como se fosse" é um sinônimo anacrônico, distorcido e confuso. E se encontra com a política de acolhimento desde a idealização da brevidade do acolhimento até a criação de vínculos malogrados em sua performatividade.

Apesar de terem sido destacados fragmentos da história José Miguel, aprende-se com seus movimentos de superação-transformação e perda-discriminação, que o retrato das instituições está marcado por paradoxos, que necessita de análise, reflexão e uma ação conduzida pela esperança que José Miguel solicita aos ouvintes da sua história ao finalizála, trazendo relatos sobre o planejamento para o futuro, contando que:

penso futuramente em ser uma pessoa melhor, que minha mãe sempre dizia pra mim não ser igual ela. Pra me ser sempre uma pessoa melhor, que ela não queria isso pra mim, nem pra minha irmã Ana. Ela sempre falou isso com nós três. Eu... Eu... Ana e a Brenda. Só que a Brenda não conseguiu e foi por esse caminho.

E pede para que finalize a sua história contando que o que ele "mais gosta de fazer é aprontar entre amigos, é... (pausa). Andar de cavalo, andar de skate. Eu gosto de coisas radicais. Gosto de cantar, gosto de música. E colocar que eu amo muito a todos".

Ao longo do desenvolvimento de uma sociedade que permita pensar para além do instituído, projeta-se que José Miguel possa perceber que ser como a mãe ou como a irmã mais velha não se explica pela simples ordem da moralidade e que haja nele caminhos e possibilidades para ser e ser visto por aquilo que ele indica no final da história. Ele é alguém permeado de gostos, sonhos e movimento. Uma pessoa em processo de transição e que, por isso também, não pode ser bem vista se assumida de forma cristalizada. 


\section{Considerações finais}

A narrativa de José Miguel possibilitou reconhecer uma história de coragem em viver metamorfoses de resistência, ainda que muitos estigmas cercassem a sua vivência. Ele é hoje alguém que se professa homossexual em "processo de transição", adolescente que vivencia os questionamentos sobre suas potencialidades de autonomia e que se encontra entre os antagonismos institucionais de viver em um lugar como se fosse uma família afinal, qual é essa família? O que é ser família?

A partir da narrativa, percebe-se que a situação de acolhimento institucional dificulta a prescrição do que no ECA (Lei nº 8069/90) é denominado como uma necessidade de "preservar a identidade", compreendendo esta como a preservação e manutenção da cultura familiar. Independentemente desta prescrição, a identidade é metamorfose e independe das condições disponibilizadas pelo abrigo. Neste, entretanto, por suas características de espaço de transição (de moradia, familiar, entre outros), é dificultado aos adolescentes a possibilidade de reestabelecer ou configurar novos vínculos afetivos (com amigos, cuidadores, funcionários etc.). O suporte no momento da mudança acaba sendo parcial, restando ao José Miguel uma história de "superação" e busca.

Portanto, a história de José Miguel enuncia a necessidade de pensarmos novas formas sociais de reconhecimento, pautadas pelo respeito à diferença e às transições. Além disso, enuncia o cuidado necessário com a criação de espaços de acolhimento que preservem vínculos, que sejam de fato recursos de última instância e que possam servir de exemplo no que se refere ao reconhecimento das singularidades dos jovens. A pesquisa reforçou a urgência da implementação de políticas públicas e ações práticas de intervenção nas questões que são antecedentes ao acolhimento, ou seja, nas condições de desigualdade, na (re)produção de preconceitos e na ausência de igualdade de oportunidades, que favorecem atuações que justificam os processos de acolhimento institucional.

\section{Notas}

1 A escolha do nome fictício para a descrição da pesquisa foi realizada pelo próprio participante, o qual apesar de ter um nome feminino, tem-se identificado na vivência do seu "processo de transição" como homem, e demarcou a importância de ter um nome masculino na pesquisa.

2 Todas as narrativas de José Miguel serão destacadas em itálico, de forma a facilitar a identificação dos momentos onde sua fala é apresentada da forma como foi transcrita. 


\section{Referências}

Aguiar, W. M. J., Bock, A. M., \& Ozella, S. (2007). A Orientação Profissional com Adolescentes: um exemplo de prática na abordagem sócio-histórica. In A. M. Bock (Org.), Psicologia Sócio-Histórica: uma perspectiva em psicologia (3a ed., pp. 163-178). São Paulo: Cortez.

Almeida, J. A. M. (2005). Sobre a Anamorfose: identidade e emancipação na velhice. Tese de Doutorado, Programa de Pós-graduação em Psicologia Social, Pontifícia Universidade Católica de São Paulo, São Paulo.

Alves, C. P. (1997a). O Adolescente, a Escola e as Políticas Públicas de Identidade. In J. J. Queiroz (Org.), Educação Hoje: Tensões e Polaridades (pp. 23-38). São Paulo: Atlântis.

Alves, C. P. (1997b). Quem sou eu? O processo de identidade de uma jovem adolescente (2a ed.). Taubaté, SP: Cabral Editora Universitária.

Austin, J. L. (1990). Quando dizer é fazer: palavras e ação. Porto alegre: Artes Médicas.

Bock, A. M. B. (2007). A adolescência como construção social: estudo sobre livros destinados a pais e educadores. Revista Semestral da Associação Brasileira de Psicologia Escolar e Educacional (ABRAPEE), 11(1), 63-76.

Butler, J. (2015a). Quadros de guerra: quando a vida é passível de luto. Rio de Janeiro: Civilização Brasileira.

Butler, J. (2015b). Problemas de Gênero: feminismo e subversão de identidade. Rio de Janeiro: Civilização Brasileira.

Ciampa, A. C. (1987/2005). A estória do Severino e a história da Severina (5a ed). São Paulo: Brasiliense. Original publicado em 1987.

Ciampa, A. C. (2002). Políticas de Identidade e Identidades Políticas. In C. I. L. Durker \& M. C. Passos (Orgs.), Uma psicologia que se interroga: ensaios (pp. 133-144). São Paulo: Edicon. Conselho Nacional dos Direitos da Criança e do Adolescente. (2009). Orientações Técnicas: Serviços de Acolhimento para Crianças e Adolescentes. Brasília - DF. Recuperado de http://www.mds.gov.br/webarquivos/publicacao/assistencia_social/Cadernos/orientacoes-tecnicas-servicos-de-alcolhimento.pdf

Conselho Nacional do Ministério Público (2013). Um olhar mais atento aos serviços de acolhimento de crianças e adolescentes no país. Relatório da Resolução $\mathrm{n}^{0} 71 / 2011$. Recuperado de https://www.cnmp.mp.br/portal/images/stories/Destaques/Publicacoes/Res 71 VOLUME 1 WEB .PDF

Ferreira, T. H. S., Aznar-Farias, M., \& Silvares, E. F. D. M. (2010). Adolescência através dos séculos. Psicologia: Teoria e Pesquisa, 26(2), 227-234.

Goffman, E. (2014). A representação do eu na vida cotidiana (20a ed.). Petrópolis, RJ: Vozez. Gonçalves, J. S. M., Lima, A. F., Miranda, L. L., \& Costa França, L. (2014). Vigiar e Assistir: Reflexões Sobre o Direito à Assistência da "Adolescência Pobre". Psicologia em Estudo, 19(2), 321-331.

Honneth, A. (2009). Luta por reconhecimento: a gramática moral dos conflitos sociais (2a ed.). São Paulo: Editora 34.

Lane, S. (1984/2012). A psicologia social e uma nova concepção do homem para psicologia. In W. Codo \& S. T. M. Lane (Orgs.), Psicologia Social: o homem em movimento (pp. 10-19). São Paulo: Brasiliense. Original publicado em 1984.

Lei n. 8069, de 13 de julho de 1990. (1990). Dispõe sobre o Estatuto da Criança e do Adolescente e dá outras providências. Brasília: Diário Oficial da União. Recuperado de http://www. planalto.gov.br/ccivil 03/leis/18069.htm

Lima, A. F. (2010). Metamorfose, anamorfose e reconhecimento perverso: A identidade na perspectiva da Psicologia Social Critica. São Paulo. FAPESP, EDUC. 
Lima, A. F. (2012) A identidade como "problema" de pesquisa. ECOS-Estudos Contemporâneos da Subjetividade, 2(2), 215-229.

Lima, A. F. (2014). História oral e narrativas de histórias de vida: a vida dos outros como material de pesquisa. In A. F. Lima \& N. Lara (Orgs.), Metodologia de Pesquisa em Psicologia Social Critica (pp. 13-34). Porto Alegre: Sulina.

Luvizaro, N. A. \& Galheigo, S. M. (2011). Considerações sobre o cotidiano e o habitar de crianças e adolescentes em situação de acolhimento institucional em abrigo. Revista de Terapia Ocupacional da Universidade de São Paulo, 22(2), 191-199.

Mayorga, C. (2006). Identidades e adolescências: uma desconstrução. Pesquisas Práticas Psicossociais, 1(1), 1-20.

Minayo, M. C. S. \& Deslandes, S. F. (2007). Pesquisa social: teoria, método e criatividade (25a ed.). Petrópolis, RJ: Vozes.

Oliveira, R. C. S. (2007). Quero voltar para casa: o trabalho em rede e a garantia do direito à convivência familiar e comunitária para crianças e adolescentes que vivem em abrigo. São Paulo: AASPTJ. Recuperado de http://www.crianca.mppr.mp.br/arquivos/File/publi/acolhimento/ quero_voltar_para casa_2010.pdf

Reis, A. O. A. \& Zioni, F. (1993). O lugar do feminino na construção do conceito de adolescência. Revista de Saúde Pública, 6(27), 472-477.

Santos, N. I. S. \& Boucinha, I. A. A. (2011). Experiência de Morar em Abrigos. Gerais: Revista Interinstitucional de Psicologia, 4(1), 36-49.

Silva, A. P., Barros, C. R., Nogueira, M. L. M., \& Barros, V. A. (2007). Conte-me sua história: reflexões sobre o método de história de vida. Mosaico: estudos em psicologia, 1(1), 25-35.

Venâncio, R. P. (2000). Família e Abandono de Crianças em uma Comunidade Camponesa de Minas Gerais: 1775-1875. Diálogos, DHI/UEM, 4(4), 111-123. 


\section{JÚLIA LOREN DOS SANTOS RODRIGUES}

\section{http://orcid.org/0000-0002-6638-8277}

Bacharel, mestre em Psicologia, Universidade Federal de São João del Rei, MG.

Endereço: Universidade Federal de São João del-Rei - UFSJ

Campus Dom Bosco - Sala 1.22

Praça Dom Helvécio, 74-Fábricas - São João del-Rei/MG - CEP: 36301-160.

E-mail: julialoren12@,hotmail.com

\section{LARISSA MEDEIROS MARINHO DOS SANTOS}

\section{http://orcid.org/0000-0003-4906-4163}

Professora do Departamento de Psicologia da Universidade Federal de São João del Rei (UFSJ), doutora em Psicologia.

E-mail: larissa@,ufsj.edu.br

\section{ALUÍSIO FERREIRA DE LIMA}

\section{http://orcid.org/0000-0001-9747-4701}

Professor do Departamento de Psicologia da Universidade Federal do Ceará, doutor em Psicologia (Psicologia Social).

E-mail: aluisiolima@,hotmail.com

\begin{tabular}{|c|c|}
\hline Histórico & $\begin{array}{l}\text { Submissão: 09/12/2018 } \\
\text { Revisão: 31/03/2020 } \\
\text { Aceite: } 20 / 04 / 2020\end{array}$ \\
\hline Contribuição dos autores & $\begin{array}{l}\text { Concepção: JLSR } \\
\text { Coleta de dados: JLSR } \\
\text { Análise de dados: JLSR, LMMS, AFL } \\
\text { Elaboração do manuscrito: JLSR, LMMS, AFL } \\
\text { Revisões críticas de conteúdo intelectual } \\
\text { importante: LMMS, AFL } \\
\text { Aprovação final do manuscrito: JLSR, LMMS, AFL }\end{array}$ \\
\hline Aprovação, ética e consentimento & $\begin{array}{l}\text { O estudo foi aprovado pelo Comitê de Ética em Pesquisa da } \\
\text { Universidade Federal de São João del Rei } \\
\text { Número do Parecer: } 2.413 .773\end{array}$ \\
\hline Financiamento & $\begin{array}{l}\text { Ao longo do desenvolvimento da pesquisa, Júlia recebeu } \\
\text { bolsa de mestrado da CAPES. } \\
\text { Aluísio Lima possui bolsa de Produtividade em Pesquisa - } \\
\mathrm{PQ} / \mathrm{CNPQ} \text {. }\end{array}$ \\
\hline
\end{tabular}

